\title{
Nalidixic Acid: Microbiological and Clinical Studies on Urinary Infections in Children
}

\author{
R. L. NEWMAN, R. J. HOLT, and C. H. FRANKCOMBE \\ From the Department of Pathology, Queen Mary's Hospital for Children, Carshalton, Surrey
}

A series of alkyl-substituted naphthyridine derivatives was synthesized by Lesher, Froelich, Gruett, Bailey, and Brundage (1962) in the early 1960 's, and one of these, nalidixic acid (1-ethyl-7methyl-1, 8 naphthyridine-4-one-3 carboxylic acid), was found to have considerable activity in vitro against the Gram-negative bacteria commonly met with in urinary infections. High urinary levels were obtained in human volunteers following moderate oral dosage. There was little ill-effect and the drug was used successfully in a series of clinical trials (Lishman and Swinney, 1963; Barlow, 1963; Ward-McQuaid, Jichlinski, and Macis, 1963). It has come to be regarded as an effective antibacterial agent for urinary infections. The purpose of this study was to assess the value of a paediatric preparation of nalidixic acid for urinary infections in children. Clinical and microbiological findings are reported of the treatment of a group of 31 patients with uncomplicated urinary infections and with infections associated with abnormalities of the urinary tract.

\section{Methods}

Nalidixic acid, supplied as a pure reference compound, is a very pale yellow crystalline powder freely soluble in dilute alkali. A $2 \%$ stock solution $(20,000 \mu \mathrm{g} . / \mathrm{ml}$.) was prepared monthly by dissolving $100 \mathrm{mg}$. in $4 \mathrm{ml}$. of $\mathrm{N} / 100 \mathrm{NaOH}$ : the $p \mathrm{H}$ was adjusted to 8.5 with $\mathrm{N} / 10$ $\mathrm{HC1}$ using phenol red as indicator and the final volume made up to $5 \mathrm{ml}$. Further dilutions in distilled water were made as required. Kept at $4^{\circ} \mathrm{C}$. the concentrated solution showed no loss of potency after one month. Although nalidixic acid is stable enough to withstand boiling or autoclaving, this proved unnecessary as no bacterial contamination occurred.

(1) Sensitivity tests (a) Discs. Sensitivity discs containing $30 \mu \mathrm{g}$. nalidixic acid supplied by Mast were found to be accurate on microbiological assay and these

Received November 15, 1965 were used throughout the trial. Even lawns of bacterial growth were cultured on infusion agar plates using an inoculum of $0.3 \mathrm{ml}$. of suspension containing about $10^{7}$ organisms $/ \mathrm{ml}$.

(b) Minimal inhibitory and bactericidal concentration (MIC and $M B C$ ). Nalidixic acid in a range of final concentrations of $0-2-5-10-20-50-100 \mu \mathrm{g} . / \mathrm{ml}$. was incorporated in $2 \mathrm{ml}$. volumes of infusion broth. The inoculum, prepared from several apparently identical colonies of an organism, was added to each tube to give a final inoculum of $10^{6}$ organisms $/ \mathrm{ml}$. After incubation for 18 hours, the tube containing the least amount of drug with no visible growth gave the MIC. Standard loop plate-outs on to MacConkey agar plates were made from each tube in the series. The MBC was regarded as the least amount of drug which prevented regrowth after 24 hours of incubation. Where required plate counts were made from tubes which showed regrowth.

(2) Drug assay. Most published assay values have been obtained by a spectrofluorimetric method which does not distinguish between microbiologically active drug and various inactive conjugates. Only Buchbinder, Webb, Anderson, La Verne, and McCabe (1962) have quoted figures obtained by microbiological methods. Since the drug readily conjugates to form these inactive compounds, and upwards of $90 \%$ of the urinary output may be in this form, it is essential for clinical purposes that a microbiological assay technique is used, the results of which represent only the active form of the drug. A wide range of assay organisms was tested, including Pasteurella multocida and other members of this genus. In our hands, a strain of Serratia marcescens proved to give the most constant and accurate zones by agar plate reservoir techniques. This organism was also unaffected by tetrazolium salts, which not only made the zones of inhibition easier to read but greatly reduced the growth of extraneous contaminating bacteria when faeces or non-catheter specimens of urine were being used.

Urine assays were performed at a dilution of 1 in 5 in distilled water. Faeces were weighed wet and extracted with $\mathrm{N} / 100 \mathrm{NaOH}$ in the proportion of $10 \mathrm{ml}$. eluent to $1 \mathrm{~g}$. wet faeces.

Spectrofluorimetric determinations of nalidixic acid were made by the method reported by McChesney, Froelich, Lesher, Crain, and Rosi (1964). 


\begin{tabular}{|c|c|c|c|c|c|c|c|c|c|c|}
\hline \multirow{2}{*}{ Organism } & & \multirow{2}{*}{ Total } & & \multicolumn{7}{|c|}{ Nalidixic Acid Concentration ( $\mu \mathrm{g} . / \mathrm{ml})}$. \\
\hline & & & & $<2$ & $2-5$ & $5-10$ & $10-20$ & $20-50$ & $50-100$ & $>100$ \\
\hline $\begin{array}{l}\text { Coliforms } \\
\text { Proteus . } \\
\text { Klebsiella }\end{array}$ & $\cdots$ & $\begin{array}{r}39 \\
33 \\
7\end{array}$ & $\begin{array}{l}\text { MIC } \\
\text { MBC } \\
\text { MIC } \\
\text { MBC } \\
\text { MIC } \\
\text { MBC }\end{array}$ & $\begin{array}{l}3 \\
0 \\
0 \\
0 \\
0 \\
0\end{array}$ & $\begin{array}{r}12 \\
2 \\
3 \\
0 \\
2 \\
0\end{array}$ & $\begin{array}{r}15 \\
1 \\
11 \\
0 \\
0 \\
0\end{array}$ & $\begin{array}{r}4 \\
6 \\
13 \\
1 \\
2 \\
2\end{array}$ & $\begin{array}{l}4 \\
8 \\
4 \\
4 \\
3 \\
0\end{array}$ & $\begin{array}{r}1 \\
11 \\
1 \\
7 \\
0 \\
0\end{array}$ & $\begin{array}{r}0 \\
11 \\
1 \\
21 \\
0 \\
5\end{array}$ \\
\hline
\end{tabular}

Note: Figures show number of strains sensitive at the levels indicated.

\section{Preliminary Laboratory Investigations}

Routine clinical isolates of Gram-negative flora (coliforms, Proteus, and Klebsiella) from all sources were tested against nalidixic acid discs, and the MIC and MBC were determined at the same time.

Zones of inhibition varied between $18 \mathrm{~mm}$. and $29 \mathrm{~mm}$. diameter, and no organism in this group was found to be totally resistant to the drug. Sometimes numerous small colonies were found within this zone, growing close to the edge of the disc. Subsequent determination in liquid media of the $\mathrm{MIC}$ and $\mathrm{MBC}$ for these colonies showed them to be considerably more resistant than the outer growth beyond the delineated zone fringe, the MIC being sometimes as much as 10 times higher. The results of the $\mathrm{MIC} / \mathrm{MBC}$ determinations are shown in Table I.

Of 39 strains of coliform tested, the MIC for 35 was between 2 and $50 \mu \mathrm{g} . / \mathrm{ml}$., while the $\mathrm{MBC}$ for 11 was over $100 \mu \mathrm{g} . / \mathrm{ml}$. With 33 Proteus strains, the MIC for 31 was between 2 and $50 \mu \mathrm{g}$. $/ \mathrm{ml}$., and the $\mathrm{MBC}$ for 21 was over $100 \mu \mathrm{g} . / \mathrm{ml}$. The MICs for all $7 \mathrm{Klebsiella}$ strains were between 2 and $50 \mu \mathrm{g} . / \mathrm{ml}$., but the MBCs for 5 were over $100 \mu \mathrm{g} . / \mathrm{ml}$.

All strains were identified as far as possible by carbohydrate fermentation and allied tests. Lactose-fermenting enterobacteria were classified as coliforms; nonlactose-fermenting enterobacteria were regarded as paracolon bacilli. No specific serotypes were included. Proteus strains were classified according to the schema of Cook (1948).

The ratios between MBC and MIC for the coliforms and Proteus strains are shown in Table II. It will be seen that high MBC/MIC ratios were found more often for Proteus than for coliform strains.

Direct correlation between disc sensitivity and MIC and $\mathrm{MBC}$ was not always obvious. In general the

\section{TABLE II}

Ratios of MBC to MIC of Coliform and Proteus Strains Shown in Table I

\begin{tabular}{|c|c|c|c|c|c|c|}
\hline$\underset{\text { Ratio }}{\text { MBC/MIC }}$ & & $>10$ & 10 & 5 & 2 & 1 \\
\hline $\begin{array}{l}\text { Coliforms } \\
\text { Proteus . . }\end{array}$ & $\ldots$ & $\begin{array}{l}12 \\
20\end{array}$ & $\begin{array}{l}8 \\
7\end{array}$ & $\begin{array}{r}10 \\
3\end{array}$ & $\begin{array}{l}6 \\
2\end{array}$ & $\begin{array}{l}3 \\
1\end{array}$ \\
\hline
\end{tabular}

smaller disc zones corresponded with higher MICs, and strains giving zones partly overgrown with small colonies frequently showed the highest $\mathrm{MBC} / \mathrm{MIC}$ ratios.

Velvet pad replica plates (Lederberg and Lederberg, 1952) were made of a number of disc inhibition zones. Where the zone was completely clear to the naked eye, no growth was seen on replication. Where the zone was overgrown, however lightly, full growth was obtained over the whole replicated area, up to the site of the original disc.

To determine whether exposure to the drug induces resistance, representative strains of coliform, Proteus, and Klebsiella were streaked on to gradient plates (Szybalski, 1952) at various inoculum sizes. In nearly every case, three or four passages were sufficient to exalt the MIC to over 100 times the original level.

\section{Clinical Investigations}

In view of these findings, treatment of a number of children with urinary infections was undertaken.

Cases were selected for treatment mainly on bacteriological grounds. Some were patients who had had numerous previous infections and others had no previous history. Initial clinical signs or suspicion of infection were confirmed by culture of numerous organisms, the presence of protein, and a marked excess of leucocytes in the urine. In cases when a Gram-negative bacillus was cultured, an immediate disc sensitivity test was carried out, followed as soon as possible by liquid titration of the MIC and MBC. Cases showing heavy infection with a Gram-negative bacillus, which gave a clear disc zone of over $20 \mathrm{~mm}$. diameter and for which the MIC was below $20 \mu \mathrm{g} . / \mathrm{ml}$., were considered suitable for treatment. Selection of cases by these criteria offered a reasonable chance of success, but a number were also treated, for whose infecting organism the MIC was up to $50 \mu \mathrm{g} . / \mathrm{ml}$., and who had a previous history of failure of treatment with other drugs. These were included in the series deliberately as 'difficult' cases.

Dosages. The recommended dose of nalidixic acid for children is $60 \mathrm{mg}$. $/ \mathrm{kg}$. day divided into 4 doses. This corresponded to 6-hourly doses of between 2 and 7 $\mathrm{ml}$. of the paediatric suspension for the children in this series. Two patients of 13 and 14 years took the drug in tablet form at the same dosage rate. Courses of treat- 
TABLE III

Sensitivity to Nalidixic Acid of Organisms from Urine of Patients Selected for Treatment

\begin{tabular}{|c|c|c|c|c|c|c|c|c|c|c|}
\hline \multirow{2}{*}{ Organism } & & \multirow{2}{*}{ Total } & & \multicolumn{7}{|c|}{ Nalidixic Acid ( $\mu \mathrm{g} . / \mathrm{ml})}$. \\
\hline & & & & $<2$ & $2-5$ & $5-10$ & $10-20$ & $20-50$ & $50-100$ & $>100$ \\
\hline $\begin{array}{l}\text { Coliforms } \\
\text { Proteus .. } \\
\text { Paracolon } \\
\text { Klebsiella }\end{array}$ & $\begin{array}{c}\cdots \\
\cdots \\
\cdots \\
\cdots\end{array}$ & $\begin{array}{r}15 \\
13 \\
5 \\
1\end{array}$ & $\begin{array}{l}\text { MIC } \\
\text { MBC } \\
\text { MIC } \\
\text { MBC } \\
\text { MIC } \\
\text { MBC } \\
\text { MIC } \\
\text { MBC }\end{array}$ & $\begin{array}{l}0 \\
0 \\
1 \\
0 \\
0 \\
0 \\
0 \\
0\end{array}$ & $\begin{array}{l}9 \\
0 \\
1 \\
0 \\
0 \\
0 \\
0 \\
0\end{array}$ & $\begin{array}{l}3 \\
1 \\
9 \\
1 \\
1 \\
2 \\
1 \\
0 \\
0\end{array}$ & $\begin{array}{l}3 \\
3 \\
2 \\
1 \\
2 \\
0 \\
1 \\
0\end{array}$ & $\begin{array}{l}0 \\
5 \\
0 \\
7 \\
1 \\
2 \\
0 \\
1\end{array}$ & $\begin{array}{l}0 \\
2 \\
0 \\
0 \\
0 \\
1 \\
0 \\
0\end{array}$ & $\begin{array}{l}0 \\
4 \\
0 \\
4 \\
0 \\
1 \\
0 \\
0\end{array}$ \\
\hline
\end{tabular}

ment varied from 4 to 14 days, mostly 6 to 9 days, depending on bacteriological response.

Control of therapy. Daily specimens of urine were examined for protein and cells, and were cultured routinely. A semi-quantitative technique for cell counting, using a centrifuged deposit of the urine and a standard high-power field, was used.

All specimens were stored at $-20^{\circ} \mathrm{C}$., tests having shown that under these conditions assay results were reproducible after as long as 4 weeks of storage. When the initial pathogen was re-isolated during treatment, the MIC and MBC were rechecked in parallel with the original isolate.

Urine assays of nalidixic acid were performed on all specimens from patients receiving treatment. Specimens were collected at varying times within the 6 hours between doses.

Clinical cases. Altogether 31 patients with urinary infections were treated: 9 of them were children who had no previous history of urinary infections and had apparently normal urinary tracts. One of these had polyneuritis and had been bedridden for several weeks, and another had diabetes insipidus. In the other 7 children of this group no predisposing cause was found.

The remaining 22 patients had a history of previous infection, in some cases many times, and all of them had anatomical abnormalities of the urinary tract. 17 of them had a meningomyelocele with accompanying urinary abnormalities, such as hydronephrosis, hydroureter, or 'neurogenic bladder'. 3 had congenitally abnormal kidneys and ureters and chronic pyelonephritis. One patient had large bilateral renal calculi with infection, and one had a history of recurrent urinary infections and enuresis, the cause of which is not yet determined. The patients' ages ranged from 6 months to 14 years, with the exception of a baby of 2 weeks.

From the cases selected for treatment, 15 strains of coliforms, 13 Proteus, 5 Paracolon, and 1 Klebsiella were isolated. Sensitivity tests in liquid medium were carried out, and the results are shown in Table III. Of the 13 Proteus strains, 10 were $P$. mirabilis, $2 P$. morgani and $1 P$. rettgeri. In 3 cases classified as mixed infections, heavy growth of 2 organisms was obtained on at least 2 successive cultures.

\section{Results}

Clinical results. Of the 31 cases treated, 21 were regarded as successful and 10 as failures. Success was judged by elimination of the infecting organism with a fall in the leucocyte count in the urine, and maintenance of sterility of the urine after treatment stopped. No definite period during which the urine remained sterile could be regarded as decisive in this respect, as the cases with abnormalities were liable to re-infection which occurred in most cases after a varying interval.

Of the 21 successful results, 8 of them were in normal children and 13 in those with abnormalities. Of the failures, only 1 of these was a normal child, the other 9 being abnormal. Treatment was successful in 8 of the 9 normal children, while of the 22 with abnormal urinary tracts only 13 were treated successfully (Table IV).

In most of the patients in whom treatment was successful the infecting organism was eliminated from the urine within 4 days of the beginning of treatment and often within 24 hours. In 2 the urine was sterile only after 6 days of treatment.

Bacteriological findings. The 34 strains isolated from the 31 patients treated fell into the following groups. Coliform: 13; Proteus: 10; Paracolon: 5; coliform + Proteus: 2; and Proteus + Klebsiella: 1.

Two of the mixed infections were of a coliform and Proteus together and one with Proteus and a

TABLE IV

Showing Success or Failure of Treatment in Patients Treated with Nalidixic Acid

\begin{tabular}{lll|c|c|c}
\hline \multicolumn{2}{c|}{ Type of Case } & & Success & Failure & Total \\
\hline Normal &. &. & 8 & 1 & 9 \\
Abnormal & $\cdots$ &. & 13 & 9 & 22 \\
\hline Total &. &. & 21 & 10 & 31 \\
\hline
\end{tabular}


TABLE V

Success and Failure of Treatment in Various Groups of Urinary Infections

\begin{tabular}{|c|c|c|c|c|c|}
\hline & & & & Successful & Unsuccessful \\
\hline $\begin{array}{l}\text { Coliforms } \\
\text { Proteus . . } \\
\text { Paracolon } \\
\text { Mixed .. }\end{array}$ & $\begin{array}{l}\ldots \\
\cdots \\
\cdots\end{array}$ & $\begin{array}{l}\ddot{ } \\
\cdots \\
\cdots\end{array}$ & $\begin{array}{c}\cdots \\
\cdots \\
\cdots\end{array}$ & $\begin{array}{r}11 \\
6 \\
2 \\
2\end{array}$ & $\begin{array}{l}2 \\
4 \\
3 \\
1\end{array}$ \\
\hline
\end{tabular}

Klebsiella. The number of patients in each group in whom treatment was successful is shown in Table V.

Development of resistance during treatment. In 8 patients, 7 of them failures, organisms were still cultured, apparently identical with the original strain, after several days of therapy. These strains showed greatly increased MIC and MBC in comparison with the initial values, sometimes as much as 10 times, and this was regarded as clear evidence of emergence of resistance to the drug in vivo. This occurred between the 2 nd and 7 th days of treatment, usually as soon as the 4th day, and was most often seen with Proteus infections (4 out of 8 ). In spite of this, however, 4 of these cases showed clinical and cytological improvement and therapy was continued. In one of them the MIC for a strain of Proteus had increased from $5 \mu \mathrm{g} . / \mathrm{ml}$. to over $500 \mu \mathrm{g} . / \mathrm{ml}$., but treatment for a further 2 days caused elimination of the organism without recurrence. The other 7 patients failed to maintain their improvement, and the infections persisted. In 5 of the 8 patients where resistance developed, the urine levels of active drug were consistently below the MBC, but in 2 the MBC was consistently exceeded. In 2 of the failures the infecting organism persisted without any increase in the MIC, though both these patients had persistently low levels of the drug in their urine: one of them was the child with diabetes insipidus who passed large quantities of dilute urine; the other was a child with congenitally abnormal kidneys and very poor renal function. In the latter, assay of the serum level of the drug gave results comparable with those obtained in other patients with normal renal function. The level of nalidixic acid in the stools also compared with that in other patients, and the failure of the drug to appear in the urine was unexplained.

Urine assays during treatment. The results of 120 urine assays are shown in Fig. 1. These were taken at various stages in the course of treatment, and it will be seen that most values lie between 0 and $200 \mu \mathrm{g} . / \mathrm{ml}$, the majority between 0 and $100 \mu \mathrm{g} . / \mathrm{ml}$. This may be accounted for by the fact, frequently observed during this investigation, that the level of active drug in the urine increased during the first day or two of treatment, becoming stabilized thereafter.

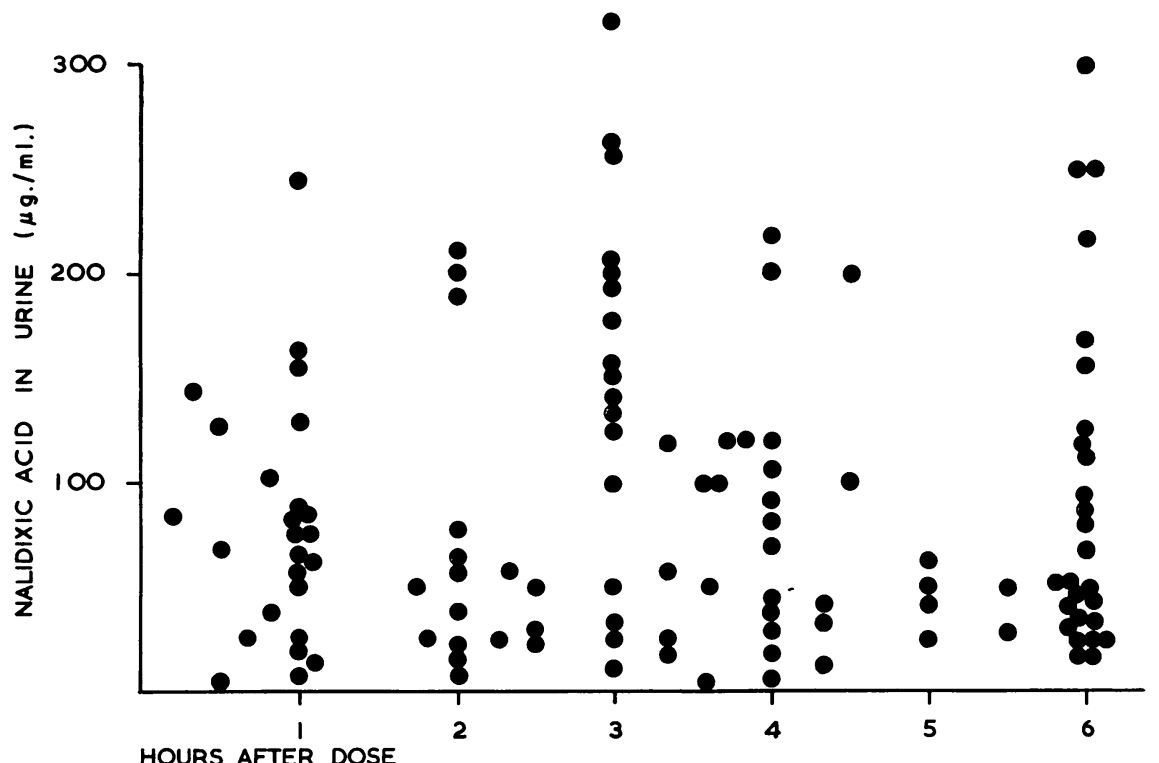

HOURS AFTER DOSE

FIG.-Nalidixic acid levels in urine from patients receiving treatment. 
The levels of the drug in the urine once treatment was established were generally stabilized at between 50 and $150 \mu \mathrm{g} . / \mathrm{ml}$.

Toxicity. Little evidence has emerged in previously published work on nalidixic acid of any serious toxic effects. Buchbinder et al. (1962) have quoted two instances of convulsions occurring in patients with disease of the central nervous system, and Belton and Vaughan Jones (1965) have recently reported a case of a baby with haemolytic anaemia thought to be due to nalidixic acid given to the mother while breast-feeding. Several workers have noted the occurrence of skin rashes during treatment. No other serious side-effects have been seen. In the present series no toxic effects whatever have been observed. Many of our patients had congenital abnormalities of the central nervous system, but careful observation has revealed no untoward effect. Poor renal function may have been a factor in failure of treatment in some of our cases but no evidence of renal damage due to the drug was seen from biochemical or cytological tests; in fact, most patients showed some improvement in this respect when their infections responded to treatment.

\section{Discussion}

There is general agreement in the published work on nalidixic acid that this drug is a useful agent for the treatment of urinary infections, and this is amply supported by the results in children reported here. This is particularly so in coliform infections, though the success rate in Proteus infections is not inconsiderable. Infections with Proteus strains are notoriously difficult to eradicate and the range of effective drugs is small. Nalidixic acid is, therefore, an important drug for use in those cases. The rapidity with which the infection was eradicated in most cases is also worthy of note. Many of the children in this series had abnormalities of the urinary tract, and the elimination of infection in these cases must be regarded as highly satisfactory. The lack of toxicity of nalidixic acid is also an important advantage. It appears that treatment may reasonably be undertaken on the results of disc sensitivity tests, provided a clear zone of inhibition is obtained with a clear-cut edge.

The over-all success rate of $67 \%$ among our patients is a little lower than that found by other workers, but some selection of patients for treatment might be expected to give a much higher success rate than this. Barlow (1963) has reported an over-all success rate in adults of $74 \%$, though nearly all his patients had coliform infections. Buchbinder et al. (1962), with less bacteriological selection, also found that in $73 \%$ of adult patients treatment was successful.

It appeared throughout our series that success depended largely on achievement of bactericidal concentrations of the active drug in the urine, and determinations of $\mathrm{MIC}$ and $\mathrm{MBC}$ were therefore important prognostically. It is evident that marked variations occur in the ratio of $\mathrm{MBC}$ to MIC among the organisms tested, and some differences emerged in our series as compared with those of other workers. Barlow (1963) has stated that for over $75 \%$ of the strains tested the MBC was the same as the MIC and the ratio was no greater than 2 in the remainder. Buchbinder et al. (1962) also found that the ratio was 1 in $80 \%$ of their cases and 4 in only $8 \%$. In our cases, low MBC/MIC ratios occurred more often with coliform strains than with Proteus and the selection of cases may account for these differences.

Barlow (1963) and Buchbinder et al. (1962) noted emergence of resistance to the drug during treatment in a proportion of cases, as also occurred in our series. The reason for this is not clear at present, as in two of our cases it could not have been due to failure to reach a bactericidal concentration in the urine. Furthermore, in one case where resistance developed, continuation of treatment resulted in elimination of the organism. Generally speaking, however, failure of treatment is nearly always associated with development of drug resistance, and the assay results show that the recommended dosage régime gives adequate urine levels in most cases. Emergence of resistance to the drug may sometimes be a problem, and persistence of the infection beyond the 4th day of treatment suggests that this has happened and indicates the need for further sensitivity tests.

In 2 of our cases, consistently low levels of nalidixic acid were found in the urine. In one, the child with diabetes insipidus, this was easily explained, but in the other the reason was not clear. It has been reported that in very young babies excretion of the drug by the kidneys occurs only very slowly, with consequent high serum levels with the usual dosage. It seemed possible that in this case poor renal function might account for a failure of excretion, but the serum level of active drug was well within the limits found in other children taking nalidixic acid in the same dosage. Failure of absorption from the bowel was also investigated by assay of the drug in the faeces. By microbiological assay normal levels were found as compared with the other patients and it is unlikely that this was the explanation. It is possible, however, that conjugation of the drug might have occurred in this case to a greater degree than in others, though spectrofluorimetric assay of the urine gave low results 
compared with other cases, and further work involving this method of assay is being undertaken to elucidate this pharmacological problem.

\section{Summary}

A trial is reported of the treatment with nalidixic acid (Negram) of 31 children with urinary infections due to Gram-negative organisms. The patients ranged from 6 months to 14 years of age, and many had congenital abnormalities of the urinary tract with a long history of urinary infections. An over-all success rate of $67 \%$ was achieved, though in coliform infections $85 \%$ of cases responded to treatment. 6 out of 10 Proteus infections were also eradicated. Emergence of resistant strains of organisms during treatment was seen in some cases, and reasons for this are discussed. Microbiological aspects of the trial are reported in some detail and suggestions are made concerning selection of cases for treatment. It appears that nalidixic acid is a valuable antibacterial agent for treating urinary infections in children. No toxic effects attributable to the drug were seen, though further work is required to determine the metabolic pathway of the drug and to explain certain anomalous results that have occurred.

We wish to express our thanks to all our colleagues at Queen Mary's Hospital for Children, for allowing access to their patients and for their kind co-operation, and we are particularly indebted to the nursing staff for collecting numerous urine specimens from patients receiving treatment.

Our thanks are also due to Mr. P. J. O'Donnell of the Bayer Products Company for generous supplies of Negram and for arranging supplies of sensitivity discs.

\section{REFERENCES}

Barlow, A. M. (1963). Nalidixic acid in infections of urinary tract: laboratory and clinical investigations. Brit. med. $\mathcal{F} ., 2,1308$. Belton, E. M., and Vaughan Jones, R. (1965). Haemolytic anaemia due to nalidixic acid. Lancet, 2, 691.

Buchbinder, M., Webb, J. C., Anderson, La Verne, and McCabe, W. R. (1962). Laboratory studies and clinical pharmacology of nalidixic acid (WIN 18,320). In Antimicrobial Agents and Chemotherapy, pp. 308-317. American Society of Microbiology, Chicago.

Cook, G. T. (1948). Urease and other biochemical properties of the Proteus group. F. Path. Bact., 60, 171.

Lederberg, J., and Lederberg, E. M. (1952). Replica plating and indirect selection of bacterial mutants. F. Bact., 63, 399.

Lesher, G. Y., Froelich, E. J., Gruett, M. D., Bailey, J. H., and Brundage, R. P. (1962). 1, 8-naphthyridine derivatives; A new class of chemotherapeutic agents. F. med. pharm. Chem., 5, 1063.

Lishman, I. V., and Swinney, J. (1963). Studies of a new antibacterial agent, nalidixic acid (WIN 18,320). Brit. F. Urol., 35, 116.

McChesney, E. W., Froelich, E. J., Lesher, G. Y., Crain, A. V. R., and Rosi, D. (1964). Absorption, excretion and metabolism of a new antibacterial agent, nalidixic acid. Toxicol. appl. Pharmacol., 6, 292.

Szybalski, W. (1952). Gradient plate technique for study of bacterial resistance. Science, 116, 46.

Ward-McQuaid, J. F. N. C., Jichlinski, D., and Macis, R. (1963). Nalidixic acid in urinary infections. Brit. med. $\mathcal{F}$., 2, 1311. 